\title{
Skeletal Muscle Remodelling as a Function of Disease Progression in Amyotrophic Lateral Sclerosis
}

\author{
L. Jensen, ${ }^{1,2}$ L. H. Jørgensen, ${ }^{1}$ R. D. Bech, ${ }^{3}$ U. Frandsen, ${ }^{2}$ and H. D. Schrøder ${ }^{1}$ \\ ${ }^{1}$ Institute of Clinical Research, Clinical Pathology, SDU Muscle Research Cluster, \\ University of Southern Denmark and Odense University Hospital, J. B. Winsløw Vej 15, 3, 5000 Odense C, Denmark \\ ${ }^{2}$ Department of Sports Science and Clinical Biomechanics, SDU Muscle Research Cluster, University of Southern Denmark, \\ Campusvej 55, 5230 Odense M, Denmark \\ ${ }^{3}$ Institute of Clinical Research, The Orthopaedic Research Unit, University of Southern Denmark and Odense University Hospital, \\ Sdr. Boulevard 29, 5000 Odense C, Denmark
}

Correspondence should be addressed to H. D. Schrøder; henrik.daa.schroeder@rsyd.dk

Received 22 December 2015; Revised 7 March 2016; Accepted 24 March 2016

Academic Editor: Alessandro Landi

Copyright (C) 2016 L. Jensen et al. This is an open access article distributed under the Creative Commons Attribution License, which permits unrestricted use, distribution, and reproduction in any medium, provided the original work is properly cited.

\begin{abstract}
Muscle weakness is considered the pivotal sign of amyotrophic lateral sclerosis (ALS). Knowledge about the skeletal muscle degeneration/regeneration process and the myogenic potential is limited in ALS patients. Therefore, we investigate these processes in a time course perspective by analysing skeletal muscle biopsies from ALS patients collected before and after a 12-week period of normal daily activities and compare these with healthy age-matched control tissue. We do this by evaluating mRNA and protein (immunohistochemical) markers of regeneration, neurodegeneration, myogenesis, cell cycle regulation, and inflammation. Our results show morphological changes indicative of active denervation and reinnervation and an increase in small atrophic fibres. We demonstrate differences between ALS and controls in pathways controlling skeletal muscle homeostasis, cytoskeletal and regenerative markers, neurodegenerative factors, myogenic factors, cell cycle determinants, and inflammatory markers. Our results on Pax7 and MyoD protein expression suggest that proliferation and differentiation of skeletal muscle stem cells are affected in ALS patients, and the myogenic processes cannot overcome the denervation-induced wasting.
\end{abstract}

\section{Introduction}

Amyotrophic lateral sclerosis (ALS), also known as motor neuron $(\mathrm{MN})$ disease, is the most common motor neuron disorder among adults [1]. ALS is characterized by degeneration of upper motor neurons leading to spasticity and lower motor neurons resulting in interruption of the nerve connection at the neuromuscular junction (NMJ) and myofibre loss $[2,3]$. The affected neuromuscular system attempts to restore function by nerve sprouting for reinnervation and by myogenesis to regenerate the muscle fibres [4]. Eventually, persistent muscle wasting exceeds the ability to repair and the consequence is progressive muscle atrophy, respiratory insufficiency, and usually death within 3-5 years of diagnosis [5]. Knowledge about the skeletal muscle degeneration/regeneration process and the myogenic potential is limited in ALS patients and has, to our knowledge, never been investigated in a time course perspective.

Muscle weakness is considered the cardinal sign of ALS and debate still exists as to whether denervation originates from the neuron or the muscle [4]. Much of our current knowledge about ALS disease progression is established within the superoxide dismutase (SOD1) G93A mouse model [6]. Previous studies show that muscle specific expression of mutant SOD1 in mice leads to an ALS phenotype and degradation of MNs $[7,8]$, demonstrating that abnormalities in skeletal muscle can induce degradation of MNs and cause ALS symptoms.

Human ALS samples are rare, but autopsy of an ALS patient demonstrated skeletal muscle changes with clear signs of denervation and reinnervation. However, the patient had normal appearing motor neurons; thus pathological changes 
TABLE 1: Clinical characteristics of ALS patients included in the study.

\begin{tabular}{lcccccc}
\hline Subject & Age & Diagnosed & Disease onset & \multicolumn{2}{c}{ Ambulation } & \multicolumn{2}{c}{ ALSFRS-R } \\
& Years & Years & BL & Walk ua & Walk ua & 42 \\
1 & 68 & $<1$ & Spinal & Walk ua & Walk ww & 40 \\
2 & 47 & $<1$ & Spinal & Walk ua & Walk ua & 38 \\
3 & 65 & $<1$ & Bulbar & Walk wb & Walk wb & 38 \\
4 & 69 & 15 & Spinal & Walk ua & Walk ww & 38 \\
5 & 57 & $<1$ & Spinal & & 43 \\
\hline
\end{tabular}

Ua: unassisted; wb: with ankle brace; ww: with walker. ALSFRS-R: ALS functional rating scale-revised.

in skeletal muscle appear to be present before the motor neurons are affected [2], thus providing human evidence for the "dying-back" phenomenon.

Healthy skeletal muscle has a remarkable ability to regenerate after injury and tissue damage. The skeletal muscle stem cells, the satellite cells (SCs), that reside under the basal lamina of muscle fibres are responsible for this repair [9]. Upon activation, the SCs become myoblasts and proliferate and differentiate to restore and replace damaged muscle fibres [10]. In vitro cultures of SCs from ALS patients demonstrate a senescent-like morphology, disturbed differentiation, and an apparent inability to proceed through the myogenic program $[11,12]$ resulting in a decreased ability to regenerate and mature to functional myofibres.

Together, these findings suggest an important role of skeletal muscle homeostasis, metabolic condition, and regenerative ability in the development of ALS. To slow down disease progression, maintenance of skeletal muscle function may be the most promising therapeutic target as of today. Thus, improved knowledge about the skeletal muscle degeneration/regeneration process is warranted, particularly in a time course perspective.

Therefore, in the present study we describe the degenerative and regenerative processes of skeletal muscle of human ALS patients and how different markers change during 12 weeks of disease progression. The hypothesis is that the myogenic program is ineffective in patients with ALS compared with healthy age-matched subjects.

\section{Materials and Methods}

Five subjects clinically diagnosed with ALS (aged $61 \pm$ $2.7 \mathrm{yrs}$ ) agreed to participate in this study. The patients were diagnosed at the Department of Neurology, Odense University Hospital according to the El Escorial criteria [13]. Four of them were diagnosed within one year from inclusion, whereas the last one was diagnosed 15 years earlier (subject 4, Figure 1). Inclusion criteria were definite or probable ALS, being ambulatory at onset of study, and willingness to comply with the study protocol. Patients were excluded for other neurological or serious medical problems including cardiovascular disease and diabetes mellitus. See Table 1 for additional clinical details. All subjects were evaluated using the revised ALS functional rating scale (ALSFRS-R) [14], which showed that all patients presented with a similar functional score at the time of inclusion and their disease symptoms showed a comparable decline over the 12-week period (Table 1), thus allowing us to group the patients for all analyses. The participants were informed about the purpose of the study and gave written informed consent before their participation. The study was conducted according to the Declaration of Helsinki and was approved by the Local Ethics Committee of the Region of Southern Denmark, Denmark.

2.1. Sample Collection. Muscle biopsies were obtained at baseline (BL) and after 12 weeks (12 wk.). They were collected from $m$. vastus lateralis under local anaesthetic (1\% lidocaine; Amgros, Copenhagen, Denmark) using a $5 \mathrm{~mm}$ Bergström needle. Biopsies were taken in the same region and depth of the weakest leg and care was taken to avoid any damaging effect of multiple biopsies [15] by separating incisions by about $5 \mathrm{~cm}$. Fifty to hundred $\mathrm{mg}$ tissue was excised and divided into multiple pieces. These were either snap-frozen in liquid nitrogen or embedded in Tissue-Tek (Sakura Finetek, Alphen aan den Rijn, Netherlands) and frozen in precooled isopentane. The samples were stored at $-80^{\circ} \mathrm{C}$ for further analysis. Furthermore, muscle biopsies were collected form healthy aged-matched control subjects $(n=7$, aged $65.1 \pm$ 0.8 yrs.) using the above protocol.

2.2. RNA Extraction and cDNA Synthesis. Tissue samples were homogenized and total RNA was extracted according to the manufacturers directions including a salt wash [16] and RNA concentration was measured using the NanoDrop (ND1000, Thermo Scientific, Copenhagen, Denmark) returning 260/280 ratios above 1.8 for all samples, and intact RNA was confirmed by denaturing agarose gel electrophoresis (Bioanalyzer; Agilent Technologies, Glostrup, Denmark). $500 \mathrm{ng}$ of RNA was converted into complementary DNA using High Capacity cDNA Reverse Transcription Kit (Applied Biosystems, Copenhagen, Denmark).

2.3. Real-Time Reverse Transcriptase Polymerase Chain Reaction. Real-time RT-PCR for ACTA1, CHRNA1, GDNF, CDK5, MYOG, MYOD1, NCAM, CD68, and PTPRC/CD45 was performed using TaqMan Low Density Arrays. Each port on the card was loaded with cDNA equivalent to $125 \mathrm{ng}$ total RNA and run at 50 cycles in triplicate on the 7900 Sequence Detection System (all reagents from Applied Biosystems, Copenhagen, Denmark). For MYF5, PAX7, P21, P27, SMAD3, and IGF1 real-time RT-PCR was performed in reactions of $25 \mu \mathrm{L}$ by mixing $6.25 \mathrm{ng}$ cDNA with appropriate TaqMan primers/probes and run in triplicate as described above. Specific primer details can be found in 

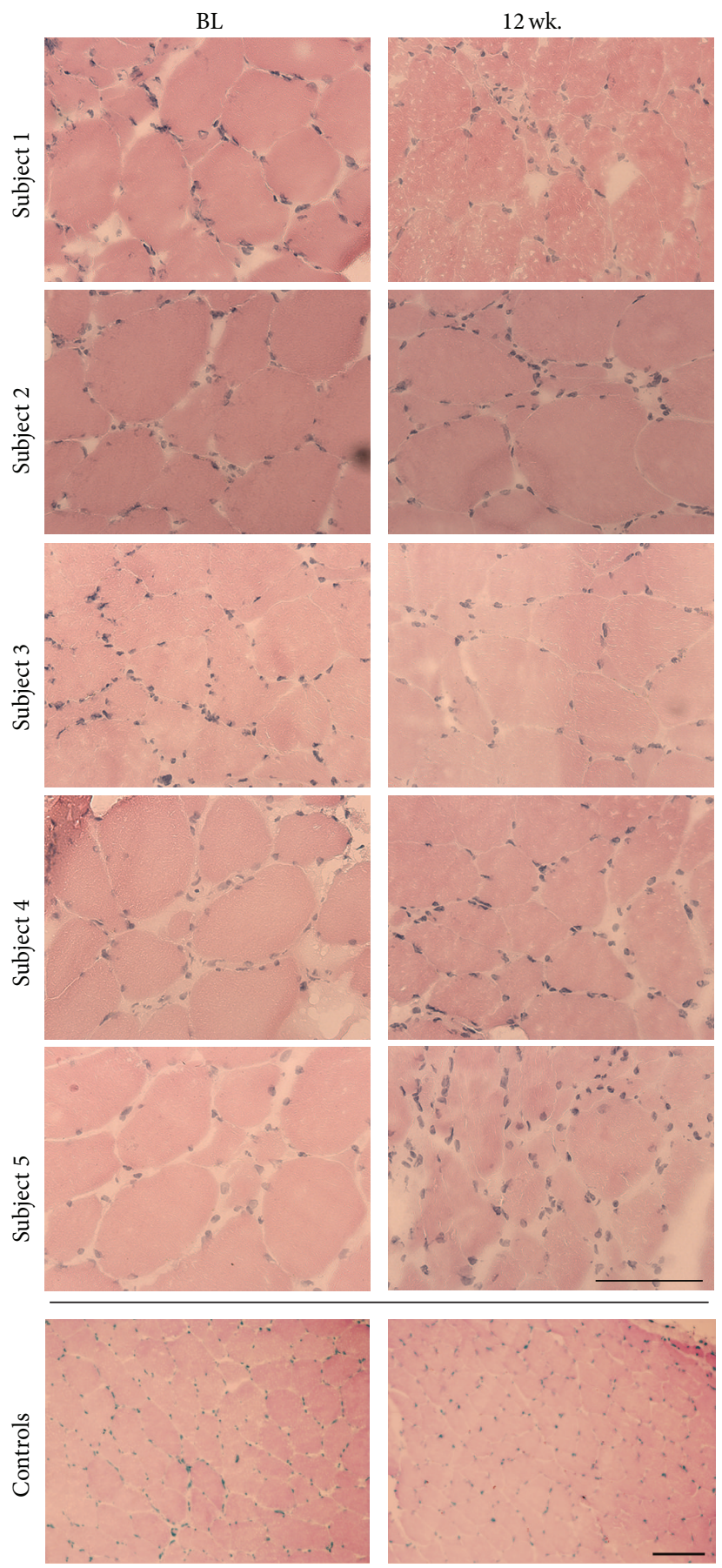

Figure 1: Morphological changes induced during 12 weeks of disease progression. Hematoxylin and eosin (HE) stainings of skeletal muscle biopsies obtained at baseline (BL) and after 12 weeks (wk.). Control samples show representative images of two healthy age-matched muscles. $n=5$ for ALS and $n=5$ for controls. Scale bar $=100 \mu \mathrm{m}$.

Table S1 "(see Supplementary Material available online at http://dx.doi.org/10.1155/2016/5930621)". Data was collected and analysed using SDS 2.4 or QuantStudio $12 \mathrm{~K}$ software (Applied Biosystems). Technical triplicates were evaluated and samples excluded when $\Delta \mathrm{Ct}>0.5$. Control genes were verified using geNorm software and data were normalized to RPLP0 and GAPDH using the qBase+ software (Biogazelle,
Zwijnaarde, Belgium) [17]. Data are scaled and presented relative to the same control sample $(=1)$ for all mRNA analyses: $n=5$ for ALS patients and $n=7$ for controls.

2.4. MicroRNA Analysis. Thirty $\mu \mathrm{g}$ total RNA was reverse transcribed using a TaqMan MicroRNA Reverse Transcription Kit (4366596) and RT primers specific for miR-1, 
miR-27b, mir-133a, miR-26a, miR-206, miR-29b, miR-23a, miR-455, and controls RNU24 and RNU6b according to manufacturers instructions. The RT products were then amplified in triplicate using sequence complementary TaqMan Small RNA assays. All reagents were from Applied Biosystems. Data was collected and analysed using SDS 2.4 and normalized to RNU24 using the qBase+ software (Biogazelle, Zwijnaarde, Belgium): $n=5$ for ALS and $n=7$ for controls.

2.5. Immunohistochemistry and Quantifications. Ten $\mu \mathrm{m} \mathrm{sec-}$ tions of frozen tissue were fixed, permeabilised, and blocked before they were incubated with primary antibodies $(1 \mathrm{~h}$, at room temperature). Primary antibodies include MHCslow 1:2000 (M8421, Sigma-Aldrich, Copenhagen, Denmark), MHC-fast 1:2000 (M4276, Sigma-Aldrich), MyoD1 1:25 (386R-16, Cell Marque/Sigma-Aldrich), Pax7 1:100 (Hybridoma Bank, Iowa City, USA), Ki67 1:100 (MiB-1, Dako), NCAM 1:100 (Leu19/MY31, BD Biosciences, Albertslund, Denmark), and CD68 1:100 (M0814, Dako). Then, ImmPRESS AP Ig polymer detection kit and Vector Blue or Vector Red AP Substrate Kit (Vector Laboratories, Herlev, Denmark), Envision+/DAB+ (K4001, K4003, and K3468, Dako, Copenhagen, Denmark), or Alexa Fluor 488 or 555 anti-mouse or anti-rabbit, accordingly 1:500 (Thermo Fisher Scientific, Denmark), were applied according to manufacturers protocols. Immunofluorescence stainings were mounted with ProLong Diamond Antifade Mountant with DAPI (Thermo Fisher Scientific). Digital image processing and analyses were performed using Axio imager M1 and AxioVision by Zeiss (Brock \& Michelsen, Copenhagen, Denmark).

In all quantifications the investigator was blinded to the identity of the patients. Cross-sectional area (CSA) of type I and type II muscle fibres was determined, and only truly transverse cut fibres were included in the analysis. The percentage of fibres belonging to every CSA interval was determined for each patient before calculating the mean. Furthermore, $\mathrm{Pax}^{+}$cells, $\mathrm{Pax}^{+} / \mathrm{MyoD}^{-}$cells, $\mathrm{Pax}^{+} / \mathrm{MyoD}^{+}$ cells, $\mathrm{MyoD}{ }^{+} / \mathrm{Ki}^{+} 7^{+}$cells, $\mathrm{NCAM}^{+}$cells, and $\mathrm{NCAM}^{+}$fibres were determined and related to the total number of fibres. At each time point $n=5$ for ALS samples and $n=3-5$ for controls due to limited control sample tissue.

2.6. Statistical Analysis. Data are presented as mean \pm SEM, apart from mRNA expression data, which were logarithmically transformed before statistical analysis and are reported in the paper as geometric means \pm SEM (back-transformed values). Paired and unpaired $t$-tests were used for statistical analyses (GraphPad Software, version 6.0, La Jolla, USA) of differences between $\mathrm{BL}$ and $12 \mathrm{wk}$. and $\mathrm{BL}$ or $12 \mathrm{wk}$. and CON for mRNA, miRNA, and immunohistochemistry stainings. Frequency distributions for CSA between BL and $12 \mathrm{wk}$. were compared using Fisher's LSD Test. Data was considered significant when $p<0.05$. Asterisk indicates significant difference from controls; ${ }^{*} p<0.05,{ }^{* *} p<0.01$, and ${ }^{* * *} p<$ 0.001 , while \# indicates significant difference between BL and $12 \mathrm{wk}$. in ALS patients. () indicates a tendency for a significant difference $(p<0.1)$.
TABLE 2: Fibre type distribution in ALS muscle.

\begin{tabular}{lcc}
\hline & BL & $12 \mathrm{wk}$. \\
\hline Total fibres (mean) & $300.8 \pm 83.5$ & $207 \pm 38$ \\
Type I (\%) & $52.5 \pm 6.3$ & $54.9 \pm 9.3$ \\
Type II (\%) & $42.7 \pm 15$ & $40.3 \pm 7.5$ \\
Mixed $(\%)$ & $4.9 \pm 2.0$ & $4.8 \pm 1.5$ \\
CSA type I $\left(\mu \mathrm{m}^{2}\right)$ & $3480 \pm 375$ & $3116 \pm 763$ \\
CSA type II $\left(\mu \mathrm{m}^{2}\right)$ & $3998 \pm 591$ & $3596 \pm 1159$ \\
CSA mixed $\left(\mu \mathrm{m}^{2}\right)$ & $5807 \pm 679$ & $3461 \pm 1040^{\#}$ \\
\hline
\end{tabular}

No significant differences are observed for any parameters except for the cross-sectional area (CSA) of mixed fibres, which is reduced at $12 \mathrm{wk}$. compared to BL $\left({ }^{\#} p<0.05\right)$.

\section{Results}

3.1. Visible Morphological Changes in ALS. Figure 1 shows $\mathrm{HE}$ stainings from ALS subjects at BL and $12 \mathrm{wk}$. and from two control samples and reveals morphological changes with increasingly disorganised muscle fibres including increased number of atrophic fibres and compensatory hypertrophy in all ALS biopsies. Subjects 2 and 5 are particularly affected by disease progression demonstrating a high degree of atrophy, compensatory hypertrophy, and areas of macrophage infiltration after 12 wk., while the remaining subjects present with milder morphological changes including the same features. Furthermore, increased amounts of inflammatory cells as well as nuclear clumps are present between the muscle fibres at 12 weeks compared to BL.

The morphological changes are supported by an increase in $\alpha$-actin (ACTA1), since $\alpha$-actin is known to be induced during active remodelling, for example, exercise and regeneration [18, 19]. Furthermore, denervation is evident by increases in the nerve and NMJ promoting factors acetylcholine receptor (CHRNA1), glial derived neurotropic factor (GDNF), and cyclin-dependent kinase 5 (CDK5), when compared to controls (Figure 2).

3.2. Changes in Fibre Type Distribution and Fibre CrossSectional Area. Baseline and $12 \mathrm{wk}$. biopsies demonstrate individual disease-induced changes in fibre type distribution and mean CSA, but none of the changes are significant at a group level (Table 2).

Immunohistochemical stainings for MHC-slow (type I fibres) and MHC-fast (type II fibres) demonstrate atrophy and compensatory hypertrophy of both fibre types (Figures $3(\mathrm{a})$ and $3(\mathrm{~b})$ ), as well as areas with fibre type grouping dominated by either type I fibres or type II fibres (Figures 3(e)-3(h)). The distribution of individual fibre CSA displays large variability in fibre size with fibres raging from below $1000 \mu \mathrm{m}^{2}$ to more than $10.000 \mu \mathrm{m}^{2}$ (Figures 3(i) and 3(j)). When comparing the frequency distributions of CSA at BL and $12 \mathrm{wk}$. there is a shift towards a smaller fibre size after $12 \mathrm{wk}$. in both type I and type II fibres $(p<0.05)$; thus ALS muscle contains a larger number of atrophic fibres at $12 \mathrm{wk}$. compared to BL. 


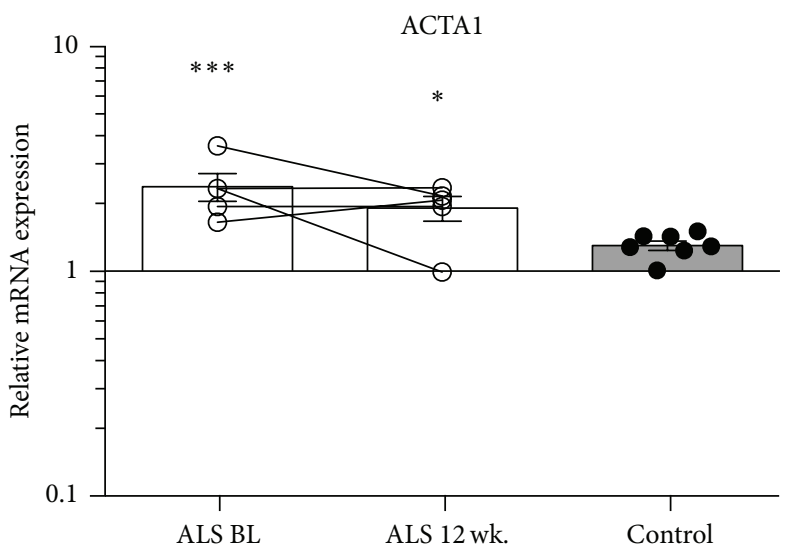

(a)

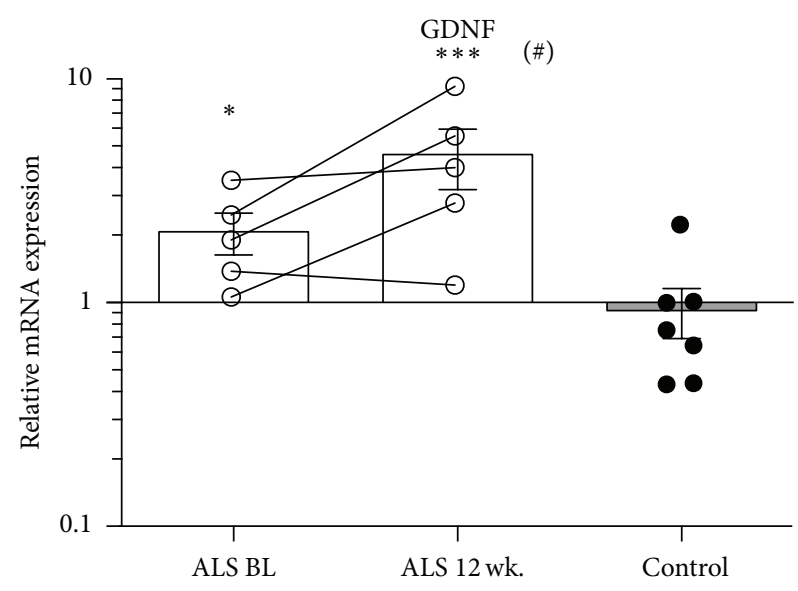

(c)

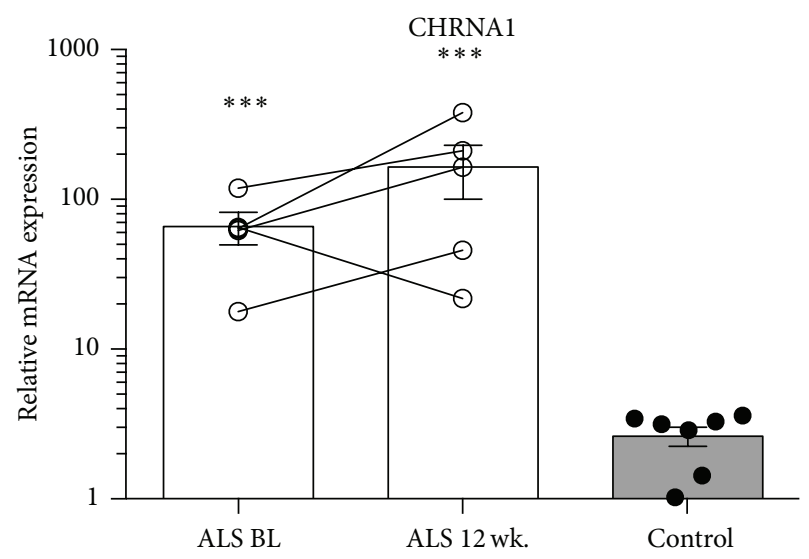

(b)

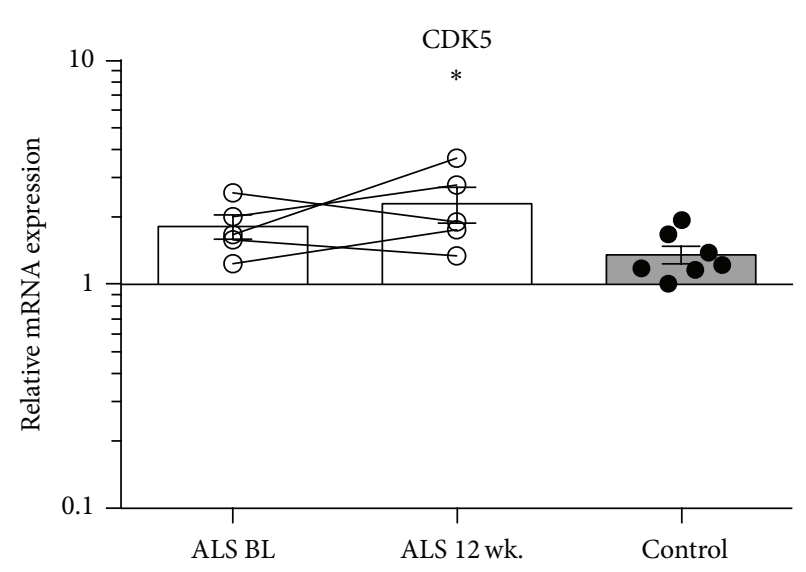

(d)

FIGURE 2: Evidence of skeletal muscle remodelling and motor neuron denervation. mRNA levels of $\alpha$-actin (ACTA1) (a), acetylcholine receptor (CHRNA1) (b), glial derived neurotropic factor (GDNF) (c), and cyclin-dependent kinase 5 (CDK5) (d) at BL and 12 wk. compared to age-matched controls ( ${ }^{\#} p<0.1$ compared to BL). Asterisks indicate significant difference from controls; ${ }^{*} p<0.05$ and ${ }^{* * *} p<0.001$.

3.3. Myogenic Changes in ALS. Skeletal muscle of ALS patients shows a reduction in mRNA levels of satellite cell and early myogenic markers PAX7 and MYF5 compared to controls, whereas the mRNA levels of the late myogenic markers myogenin (MYOG) and MYOD1 are increased (Figures 4(a)-4(d)). The mRNA levels of MYOG and MYOD1 are increased at $12 \mathrm{wk}$. compared to $\mathrm{BL}$, although this does not reach statistical significance.

The mRNA results suggest that the satellite cells might be affected in the ALS patients. We therefore analysed the activation status of the satellite cells using immunohistochemistry. $\mathrm{Pax}^{+}$cells were found next to both hypertrophied fibres (Figures 4(e) and 4(f), arrows) and in smaller fibres (Figure 4(f), arrowhead). The overall number of $\mathrm{Pax}^{+}$cells/fibre did not change between BL and $12 \mathrm{wk}$. (Table 3 ). To investigate whether the satellite cells are activated or are resting we performed double immunofluorescence staining for Pax7 and MyoD. We find that that very few $\mathrm{Pax}^{+}$cells express MyoD $\left(\mathrm{Pax}^{+} / \mathrm{MyoD}^{+}\right)$; thus the majority of the $\mathrm{Pax} 7^{+}$satellite cells are negative for MyoD (Table 3 and Figures 4(g)-4(i)). On an interesting note, we observed a large amount of MyoD positive nuclei in the tissue in general for all patients (Figures $4(\mathrm{~g})$ and $4(\mathrm{j}))$. To evaluate whether these $\mathrm{MyoD}^{+}$cells were in an active proliferative state or postmitotic, we performed a $\mathrm{Ki} 67^{+} / \mathrm{MyoD}^{+}$double immunofluorescence staining. Here we found that very few MyoD ${ }^{+}$cells expressed Ki67, and in general there were almost no Ki67 expressing cells in the tissue (Table 3 and Figures $4(j)-4(1)$ ).

To further evaluate myogenic changes in ALS muscle we analysed expression of NCAM. We observe that NCAM mRNA levels are highly increased in ALS compared to controls (Figure 5(a)). Immunohistochemistry for NCAM protein demonstrates NCAM expression in both single cells and individual fibres, which are mainly atrophic fibres (Figures 5(b) and 5(c)), whereas controls show a few $\mathrm{NCAM}^{+}$ satellite cells (Figure 5(d)). The disease progression induces a decrease in $\mathrm{NCAM}^{+}$fibres for all ALS subjects, which trends to reach statistical significance ( $p=0.078$ ), but no changes in $\mathrm{NCAM}^{+}$cells are observed (Figures 5(e) and 5(f)).

3.4. Alterations in myomiRs, Cell Cycle Regulators, and Inflammation in ALS. Skeletal muscle specific microRNAs (myomiRs) 1, 26a, and 133a along with miR-455 are reduced in ALS compared to controls (Figure 6(a)); however, disease 


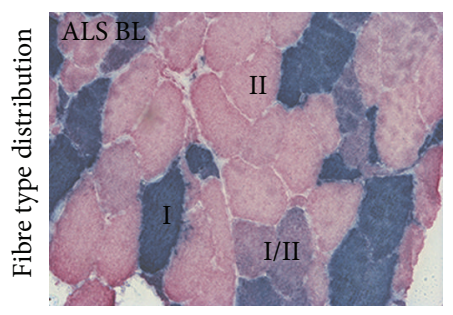

(a)

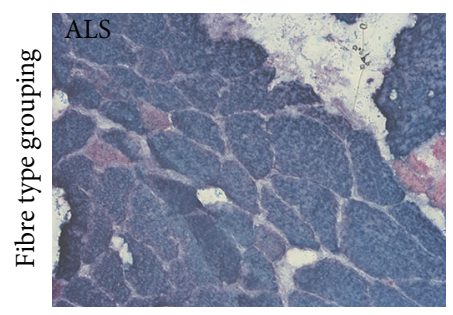

(e)

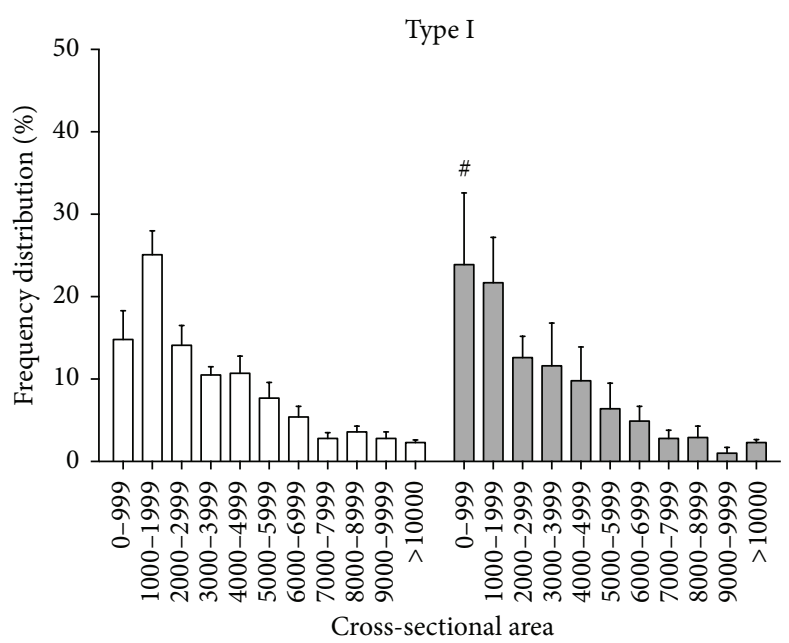

$\square \mathrm{BL}$

$\square 12 \mathrm{wk}$.

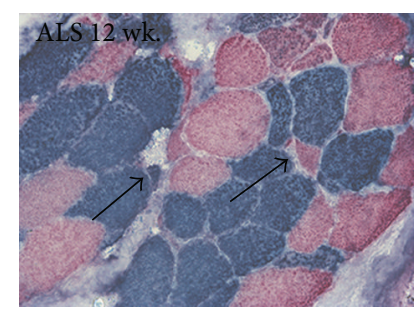

(b)

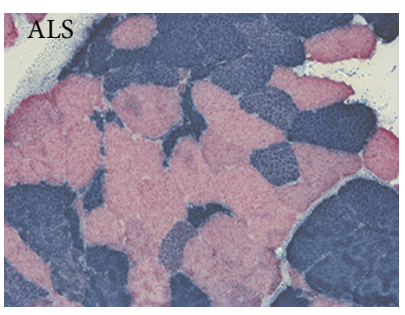

(f)

Type I

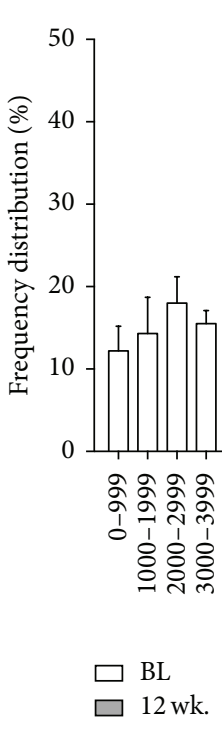

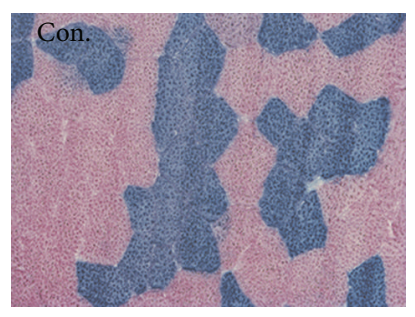

(c)

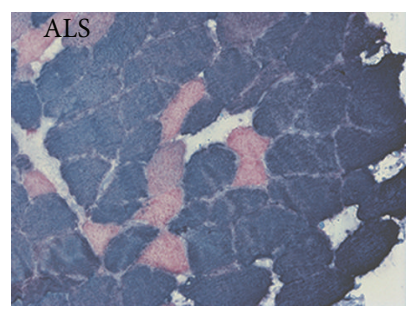

(g)

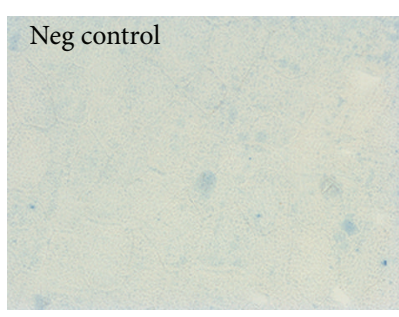

(d)

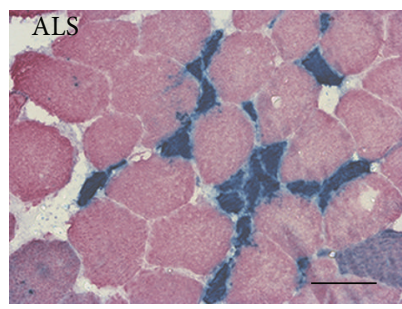

(h)

Type II

(i)

(j)

FIGURE 3: Skeletal muscle of ALS patients presents with atrophy of both type I and type II fibres. (a and b) Representative images of immunohistochemical stainings for fibre type distribution show MHC-slow in blue, MHC-fast in red, and mixed/changing fibres in purple. Atrophic fibres of both type I and type II can be seen in the same individual (b, arrow). (c) Control samples show even distribution of fibres with similar size and no mixed fibres. (e-h) Representative images of fibre type grouping and fibre type-specific atrophy in ALS muscle. (I and j) Frequency distribution of cross-sectional area at BL and $12 \mathrm{wk}$. for type I (i) and type II (j) fibres. CSA: cross-sectional area. Significant differences between BL and $12 \mathrm{wk}$. in ALS in CSA for both fibre types are indicated by ${ }^{\#} p<0.05 . n=5$ for ALS and $n=3$ for controls. Scale bar $=50 \mu \mathrm{m}$.

progression does not induce further change between $\mathrm{BL}$ and $12 \mathrm{wk}$. mRNA expression of cyclin-dependent kinase inhibitor 1A (p21) is induced, while cyclin-dependent kinase inhibitor $1 \mathrm{~B}$ (p27) and mothers against decapentaplegic homolog 3 (SMAD3) mRNA transcripts are reduced compared with controls (Figures 6(b)-6(d)). Insulin-like growth factor 1 (IGF1), an inducer of muscle tissue growth, is not affected in ALS compared to controls (Figure 6(e)). Both mRNA levels of CD68 and CD45 along with protein expression of CD68 demonstrated higher levels of inflammatory cells in skeletal muscle of ALS patients compared to controls
(Figure 7). The $\mathrm{CD}^{+} 8^{+}$cells were localized mainly in the connective tissue between muscle fibres.

\section{Discussion}

In this paper we describe the degenerative and regenerative processes in skeletal muscle of ALS patients over a shortterm period to observe disease development and progression. Moreover, we compare the skeletal muscle of ALS patients to that of healthy, age-matched muscle. We find morphological changes in ALS muscle indicative of active denervation and 


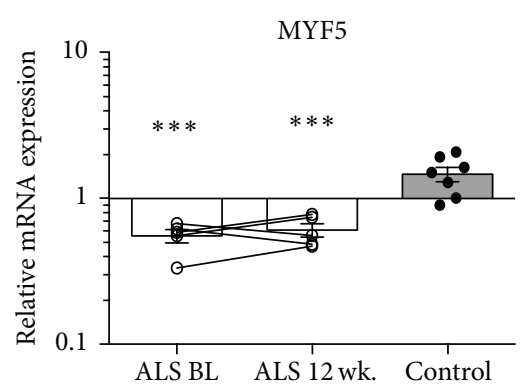

(a)

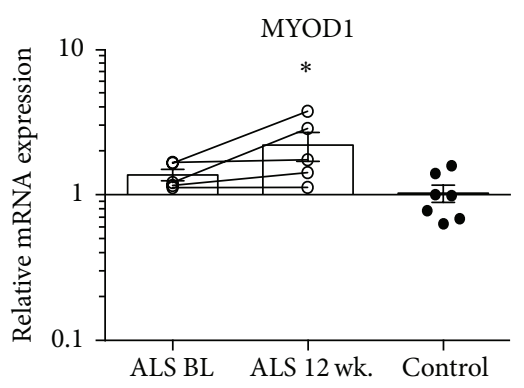

(d)

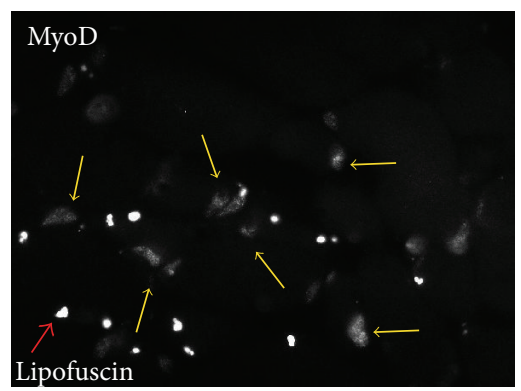

(g)

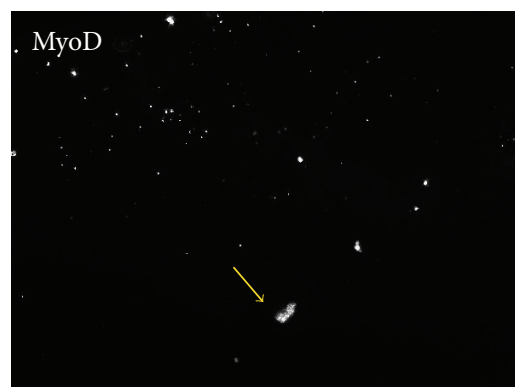

(j)

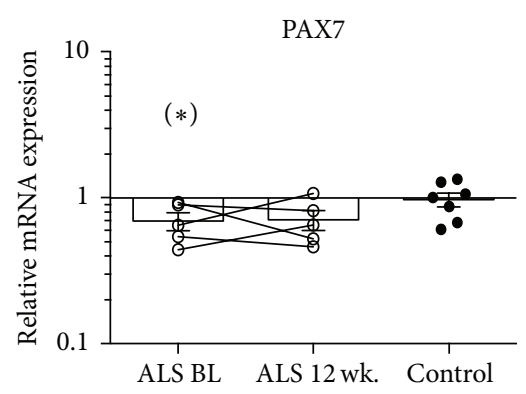

(b)

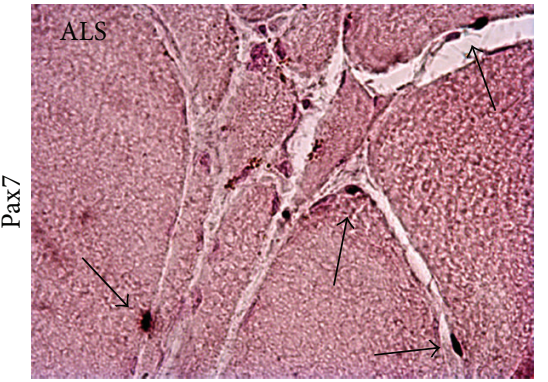

(e)

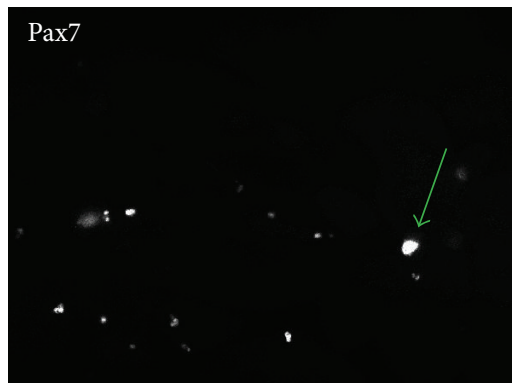

(h)

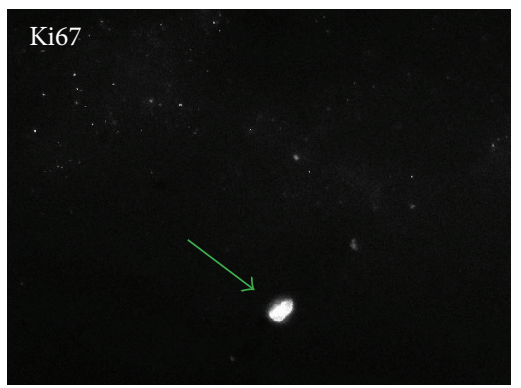

(k)

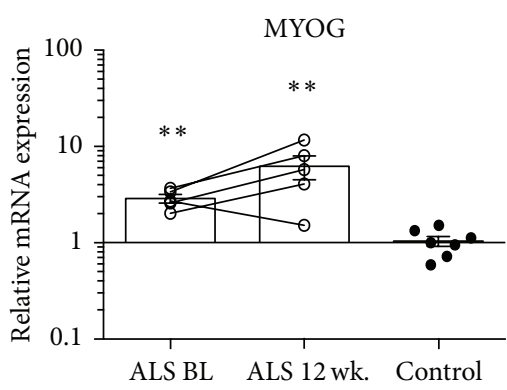

(c)

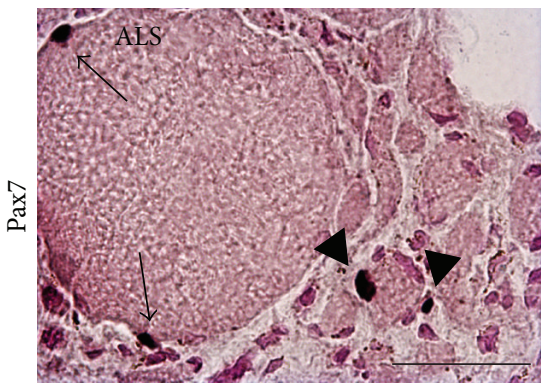

(f)

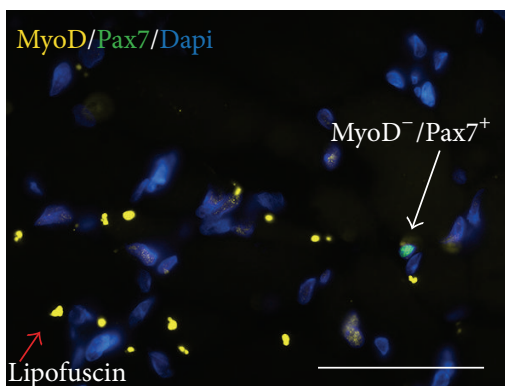

(i)

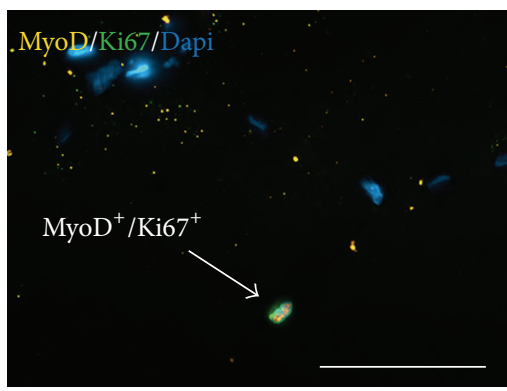

(1)

FIgURE 4: Myogenesis in ALS muscle. mRNA transcripts of (a) MYF5, (b) PAX7, (c) MYOG, and (d) MYOD1 in ALS during disease progression compared to controls. (e and f) Representative immunohistochemical images of Pax $7^{+}$cells in ALS muscle. Arrows indicate $\mathrm{Pax}^{+}$cells associated with hypertrophied fibres and arrowheads indicate Pax ${ }^{+}$cells associated with atrophic fibres. (g-i) Double immunofluorescence stainings of MyoD (yellow), Pax7 (green), and DAPI (blue). (j-1) Double immunofluorescence stainings of MyoD (yellow), Ki67 (green), and DAPI (blue). $\left({ }^{*}\right) p<0.1,{ }^{*} p<0.05,{ }^{* *} p<0.01$, and ${ }^{* * *} p<0.001$. In (a-d) $n=5$ for ALS and $n=7$ for controls and in $(\mathrm{g}-\mathrm{l}) n=5$ for ALS. Scale bar $=50 \mu \mathrm{m}$ for all images.

reinnervation along with a reduction in CSA, yet none of the examined mRNA markers change significantly within the 12 -week time period. However, we demonstrate differences between ALS and controls in pathways controlling skeletal muscle homeostasis, cytoskeletal and regenerative markers, neurodegenerative factors, myogenic factors, cell cycle determinants, and inflammatory markers.

Upper and lower motor neuron injuries induce different morphological changes, revealing a preferential type II fibre atrophy and type I hypertrophy and muscle fibre group 


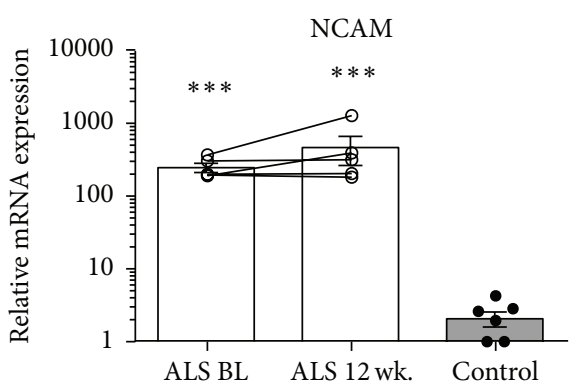

(a)

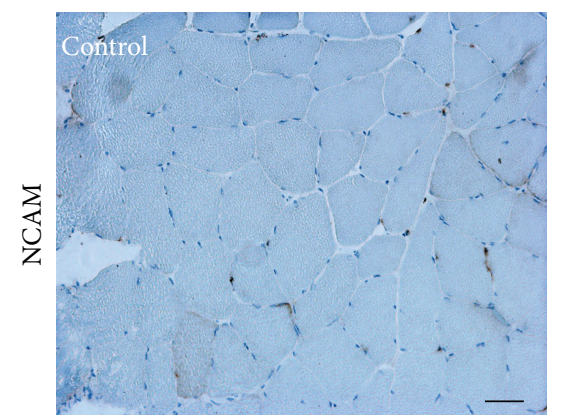

(d)

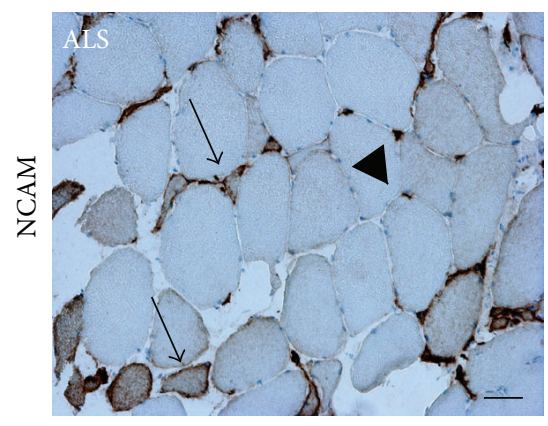

(b)

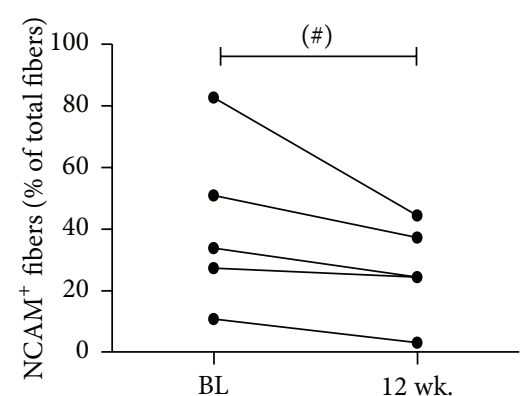

(e)

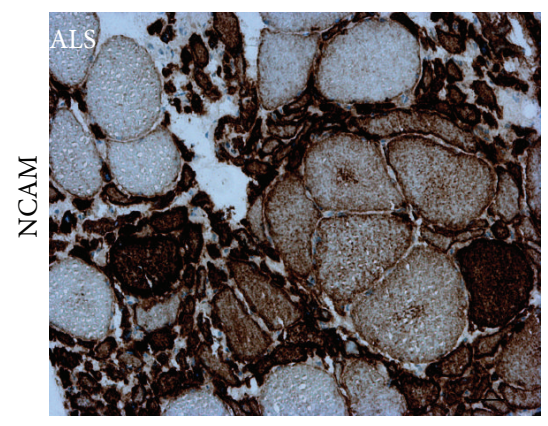

(c)

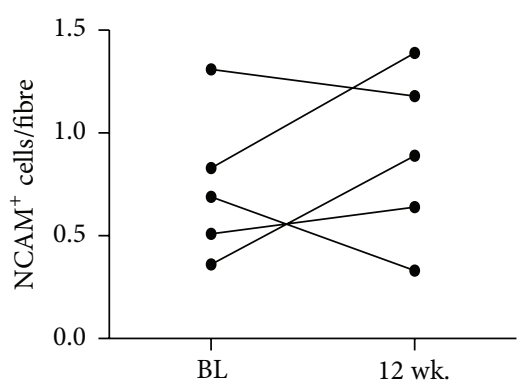

(f)

FIgURE 5: NCAM in ALS. (a) NCAM mRNA transcript in ALS during disease progression compared to controls. (b and c) Immunohistochemical staining for NCAM (blue) showed positive fibres (arrows) and cells (arrowheads) in ALS, but no staining except for a few positive satellite cells in controls (d). Stereological analysis of $(\mathrm{e}) \mathrm{NCAM}^{+}$fibres $\left({ }^{\#} p=0.078\right)$ and (f) $\mathrm{NCAM}^{+}$cells. Asterisk indicates significant difference from controls; ${ }^{* * *} p<0.001$. In (a) $n=5$ for ALS and $n=7$ for controls. In (b-f) $n=5$ for ALS. Scale bar $=50 \mu \mathrm{m}$.

TABLE 3: Analysis of activation status of satellite cells in ALS.

\begin{tabular}{|c|c|c|c|c|c|}
\hline Subject & $\operatorname{Pax} 7^{+}$ & Pax7 $7^{+} /$fibre & $\mathrm{Pax}^{+} / \mathrm{MyoD}^{-}$ & $\mathrm{Pax}^{+} / \mathrm{MyoD}^{+}$ & $\mathrm{Ki} 67^{+} / \mathrm{MyoD}^{-}$ \\
\hline \multicolumn{6}{|l|}{$\mathrm{BL}$} \\
\hline 1 & 13 & 0.071 & 12 & 2 & 1 \\
\hline 2 & 32 & 0.066 & 30 & 2 & 2 \\
\hline 3 & 26 & 0.074 & 23 & 3 & 0 \\
\hline 4 & 11 & 0.092 & 11 & 0 & 1 \\
\hline 5 & 22 & 0.068 & 22 & 0 & 0 \\
\hline Mean \pm SEM & $20.8 \pm 3.9$ & $0.074 \pm 0.005$ & $19.6 \pm 3.6$ & $1.4 \pm 0.6$ & $0.8 \pm 0.37$ \\
\hline \multicolumn{6}{|l|}{$12 \mathrm{wk}}$. \\
\hline 1 & 10 & 0.057 & 9 & 1 & 0 \\
\hline 2 & 10 & 0.067 & 9 & 1 & 0 \\
\hline 3 & 21 & 0.088 & 21 & 0 & 1 \\
\hline 4 & 23 & 0.099 & 23 & 0 & 0 \\
\hline 5 & 25 & 0.091 & 25 & 0 & 0 \\
\hline Mean \pm SEM & $17.8 \pm 3.25$ & $0.080 \pm 0.01$ & $17.4 \pm 3.5$ & $0.4 \pm 0.2$ & $0.2 \pm 0.2$ \\
\hline
\end{tabular}

Satellite cells/myoblast in BL and 12 wk. patient samples were stained for expression of Pax7, MyoD, and Ki67 using immunofluorescence and evaluated by counting. The number of identified cells in each section is noted.

atrophy and fibre type grouping, respectively [20]. Previous studies have evaluated muscle morphometry in ALS patients [21] and neuromuscular disorders [22] and described characteristic features as a mix of the above with muscle fibre atrophy and hypertrophy and a large degree of fibre type grouping, which is in line with our findings. Our results demonstrate a reduction in CSA from BL to $12 \mathrm{wk}$. and a large variability in fibre CSA ranging from below $100 \mu \mathrm{m}^{2}$ to over $18.000 \mu \mathrm{m}^{2}$ indicating an active remodelling process with atrophy of some fibres and compensatory hypertrophy in others, the latter in order to overcome the loss of muscle fibres. The fact that we do not find a significant increase in hypertrophied fibres is likely a matter of lack of power, as we do see a tendency for an increase. Higher levels in $\alpha$-actin 


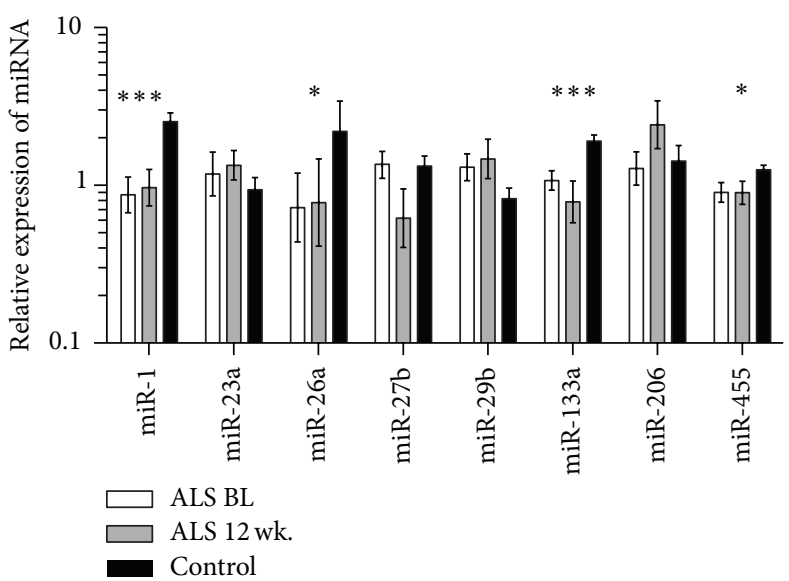

(a)

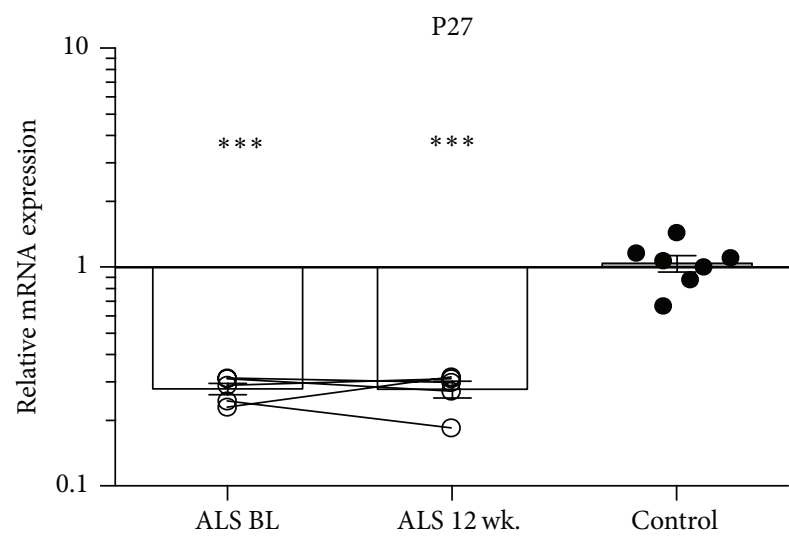

(c)

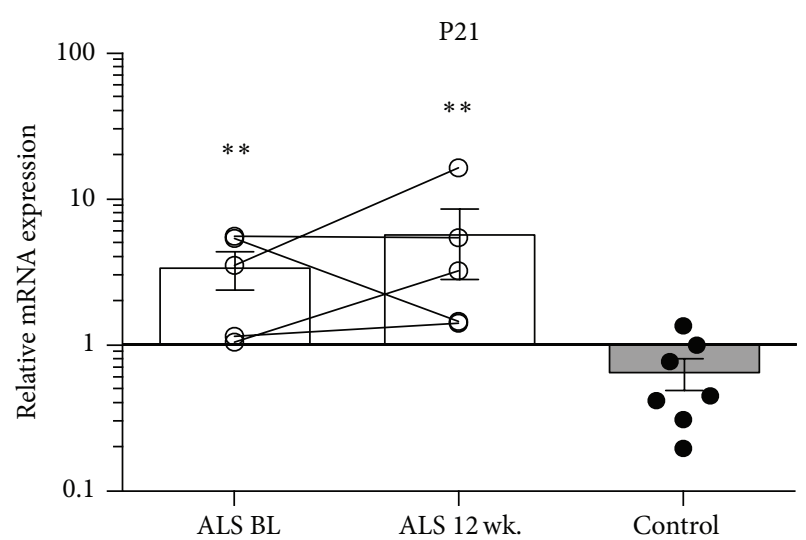

(b)

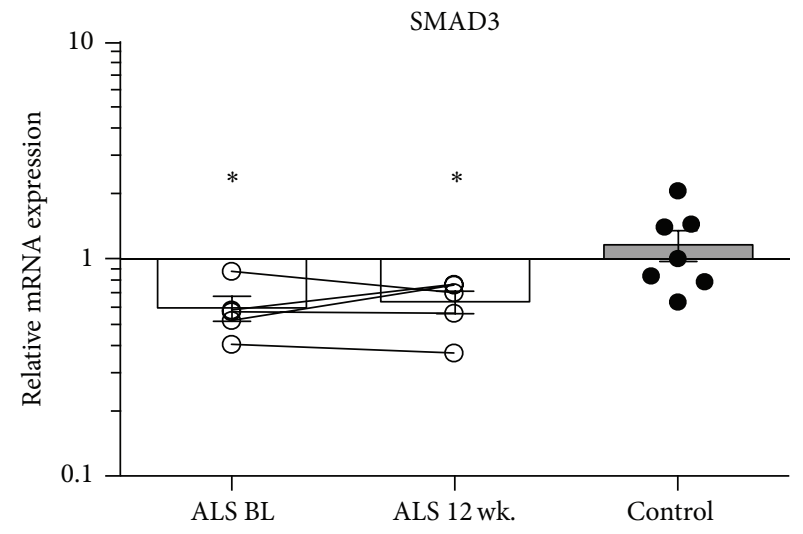

(d)

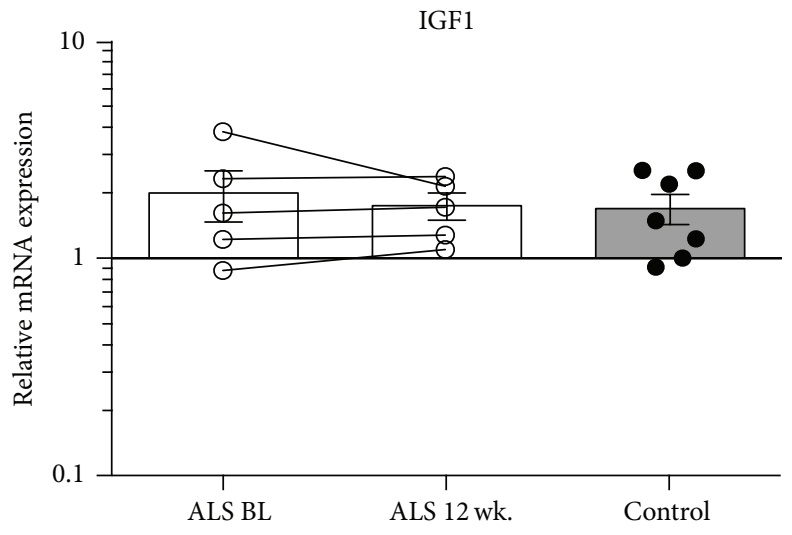

(e)

Figure 6: Cell cycle regulation and muscle specific microRNAs in ALS patients. (a) Expression of miR-1, miR-133a, miR-206, and miR-455 in ALS patients compared to controls. (b-e) mRNA transcript in ALS during disease progression compared to controls for (b) p21, (c) p27, (d) SMAD3, and (e) IGF-1. $n=5$ for ALS samples and $n=7$ for controls. Asterisks indicate significant differences from controls; ${ }^{*} p<0.05$, ${ }^{* *} p<0.01$, and ${ }^{* * *} p<0.001$.

mRNA levels compared to controls further underline this, as active remodelling leads to an activation of the $\alpha$-actin promoter [19].

In line with this, our data show substantially elevated NCAM mRNA levels compared to controls, and high muscle fibre NCAM protein expression also suggests that regeneration is activated [23]. NCAM ${ }^{+}$fibres in ALS can represent both denervated and regenerating fibres, and the observed decrease in $\mathrm{NCAM}^{+}$fibres from BL to $12 \mathrm{wk}$. could be a result of either an exhausted or an impaired regeneration. It must 


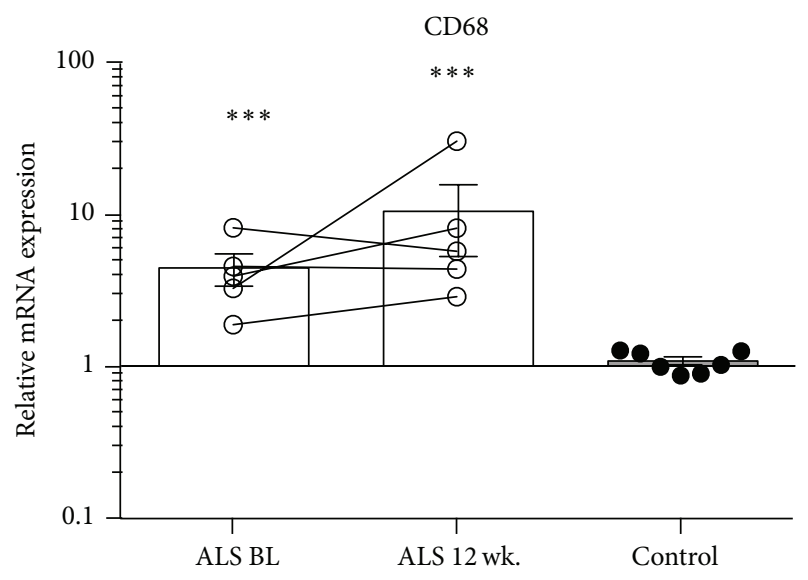

(a)

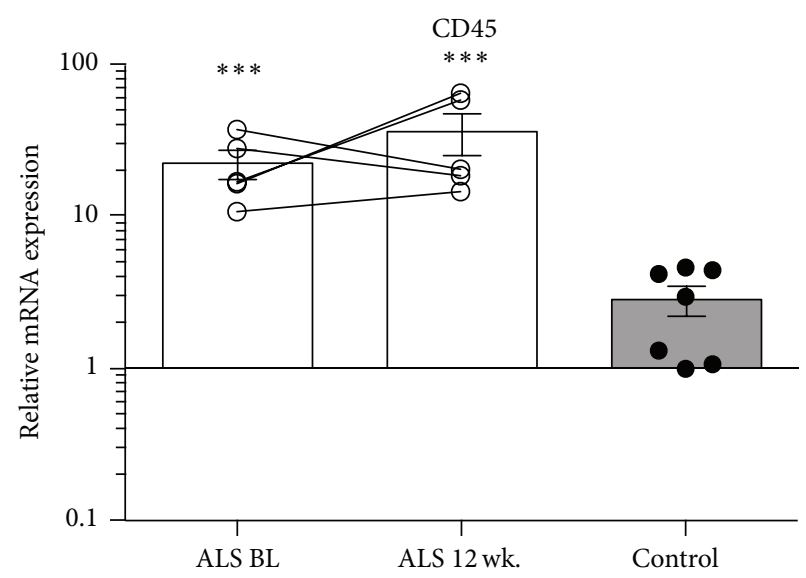

(b)

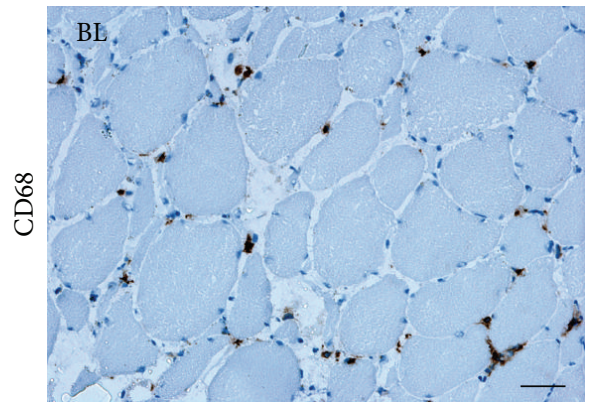

(c)

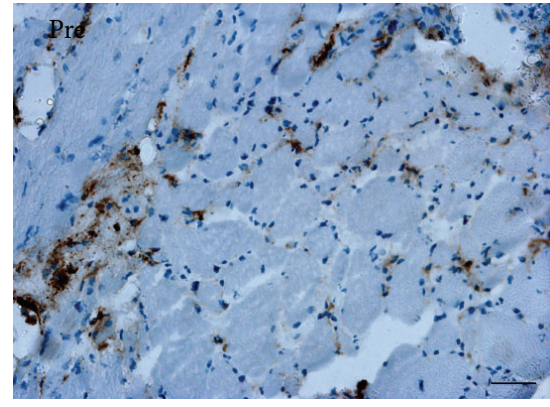

(d)

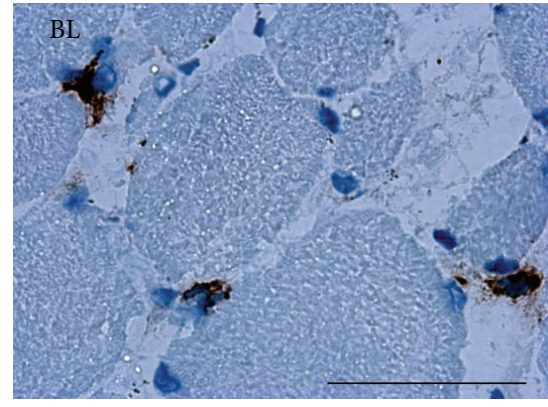

(e)

Figure 7: Active tissue inflammation to assist in cellular repair. (a and b) Expression levels of CD68 and CD45 mRNA. (c-e) Representative images of tissue macrophages at both $\mathrm{BL}$ and $12 \mathrm{wk}$. time points with a localized distribution in the interstitium between muscle cells. In (a and b) $n=5$ for ALS and $n=7$ for controls. In (c-e) $n=5$ for ALS. Asterisks indicate significant differences from controls; ${ }^{* * *} p<0.001$. Scale bar $=50 \mu \mathrm{m}$.

be kept in mind that it is the number of $\mathrm{NCAM}^{+}$fibres that have been evaluated, rather than the expression level of each fibre, which might change over time.

Denervated, atrophic myofibres tend to become angular and eventually result in "nuclear clumps" with little or no cytoplasm left [24], while new myogenic fibres are small and round [25]. We find that $\mathrm{NCAM}^{+}$fibres in ALS patients are mainly small and angular, which suggest that these are denervated fibres rather than newly formed, regenerating fibres.

As a measure of the myogenic potential we evaluated the number of Pax $7^{+}$satellite cells in ALS skeletal muscle. Previous studies have established satellite cell numbers of young and old individuals to be around $0.05 \mathrm{Pax}^{+}$cells/fibre [26] and around the same magnitude in ALS patients [27]. Our data of $\mathrm{Pax} 7^{+}$cells/fibre is in line with previous findings [26], indicating that satellite cells are present for potential activation [28]. We therefore performed double stainings for MyoD and Pax7 to evaluate the actual activation status of the $\operatorname{Pax} 7^{+}$cells present in ALS muscle. We find that very few $\mathrm{Pax}^{+}$cells express MyoD, suggesting that the satellite cells are in a nonactive, resting state and are not activated. However, since we find the presence of many $\mathrm{MyoD}^{+} / \mathrm{Ki} 67^{-}$ cells, this points out that there has been activation of satellite cells to regenerate the muscle; however, this process has somehow been halted or distorted due to the ALS pathology.

The higher expression levels of MYOD1 and MYOG mRNA in ALS muscle could indicate an activated differentiation process. When analysing expression of $\mathrm{MyoD}$ on protein level we observe a high amount of $\mathrm{MyoD}^{+}$cells in general, thus corresponding to the increased expression on mRNA level as well. A double staining for $\mathrm{MyoD}$ and the proliferation marker Ki67 reveals that only few of the $\mathrm{MyoD}^{+}$cells are in an active proliferative state, suggesting that the activated muscle cells are kept in a $\mathrm{MyoD}^{+}$postmitotic state. Whether this is due to a long differentiation period or the cells are arrested at this stage needs further investigation. However, it is known that both MYOD1 and MYOG are regulated by electrical stimulation [29]; thus the findings on changes in MyoD on both mRNA and protein level might reflect the changed neural activity in these patients. The observation of reduced early myogenic markers in combination with increased late myogenic markers probably reflects the disease pattern in skeletal muscle of ALS patients.

Denervation is one of the earliest signs of ALS and in line with this the denervation-induced markers CHRNA1, GDNF, and CDK5 are all highly expressed in the ALS patients as we expected. The sensitive nature and large increase of CHRNA1, 
GDNF, and CDK5 in ALS muscle allow these to be potential biomarkers of ALS disease development and progression.

In the present study we also investigated the mechanisms of cell cycle progression and skeletal muscle growth to evaluate if disturbances in the expression of myomiRs or cell cycle regulators could influence the remodelling and regeneration capacity of ALS skeletal muscle. MicroRNAs are tight regulators of cell fate and tissue homeostasis [30], and our results show that miR-1, miR-133a, and miR-206 are all reduced in ALS muscle suggesting that both myogenic proliferation and differentiation might be altered. Inhibition of miR-1 and miR-206 blocks the downregulation of most targets in differentiating cells, thus indicating that they are required for muscle differentiation [31], while miR-133 expression is attenuated during the early stage of muscle regeneration and represses myoblast proliferation [32]. MiR-206 has also been identified as an important player in the repair of the NMJ following nerve injury [33], and one study has identified miR206 as a potential disease marker in SOD-1 mice and ALS patients [34]. Thus miRs appear to be important players in ALS disease progression and muscle restoration.

Multiple studies have identified interactions between miR-1 and IGF-1 showing an inverse relationship between these $[35,36]$. We observed a reduction in miR-1 combined with no change in IGF-1 mRNA, which may be due to an insufficient reduction of miR-1, or the interactions between miR-1 and IGF-1 do not play a role in ALS.

We find that p21 mRNA expression is induced in the ALS patients, suggesting that myogenic cells have entered the differentiation and maturation process and thus no longer proliferate [37-39]. This is supported by our findings of $\mathrm{MyoD}^{+} / \mathrm{Ki} 67^{-}$cells. Likewise, our data show a reduction in p27 mRNA in ALS patients compared to controls [40, 41], which is in line with our findings of the presence of primarily nonactivated satellite cells.

The present study has several limitations. The small number of ALS patients studied here and the heterogeneous disease progression and clinical presentation seen in ALS patients in general limit our ability to generalise our findings to larger populations of ALS patients. However, a major strength of the present study is the longitudinal collection of muscle biopsies, which is unique in ALS patients.

Altogether, our results suggest that activation, proliferation, and differentiation of skeletal muscle stem cells are affected and possibly halted in ALS patients and there is therefore a generally insufficient myogenesis that cannot overcome the denervation-induced wasting. It would therefore be necessary to understand which mechanisms are affected in order to impact on the myogenic program if we are to diminish disease progression and skeletal muscle atrophy in ALS patients in the future.

\section{Competing Interests}

The authors declare that they have no competing interests.

\section{Acknowledgments}

The authors would like to thank the ALS patients for their participation in the study. This study was supported by grants from the Bevica Foundation and the Hede Nielsen Family Foundation.

\section{References}

[1] S. S. Gubbay, E. Kahana, N. Zilber, G. Cooper, S. Pintov, and Y. Leibowitz, "Amyotrophic lateral sclerosis. A study of its presentation and prognosis," Journal of Neurology, vol. 232, no. 5, pp. 295-300, 1985.

[2] L. R. Fischer, D. G. Culver, P. Tennant et al., "Amyotrophic lateral sclerosis is a distal axonopathy: evidence in mice and man," Experimental Neurology, vol. 185, no. 2, pp. 232-240, 2004.

[3] J. Hegedus, C. T. Putman, and T. Gordon, "Time course of preferential motor unit loss in the SOD $1^{\mathrm{G} 93 \mathrm{~A}}$ mouse model of amyotrophic lateral sclerosis," Neurobiology of Disease, vol. 28, no. 2, pp. 154-164, 2007.

[4] M. Dadon-Nachum, E. Melamed, and D. Offen, "The 'dyingback' phenomenon of motor neurons in ALS," Journal of Molecular Neuroscience, vol. 43, no. 3, pp. 470-477, 2011.

[5] A. Chio, G. Logroscino, O. Hardiman et al., "Prognostic factors in ALS: a critical review," Amyotrophic Lateral Sclerosis, vol. 10, no. 5-6, pp. 310-323, 1992.

[6] M. E. Gurney, H. Pu, A. Y. Chiu et al., "Motor neuron degeneration in mice that express a human $\mathrm{Cu}, \mathrm{Zn}$ superoxide dismutase mutation," Science, vol. 264, no. 5166, pp. 1772-1774, 1994.

[7] M. Wong and L. J. Martin, "Skeletal muscle-restricted expression of human SOD1 causes motor neuron degeneration in transgenic mice," Human Molecular Genetics, vol. 19, no. 11, pp. 2284-2302, 2010.

[8] G. Dobrowolny, M. Aucello, E. Rizzuto et al., "Skeletal muscle is a primary target of SOD1 ${ }^{\mathrm{G} 93 \mathrm{~A}}$-mediated toxicity," Cell Metabolism, vol. 8, no. 5, pp. 425-436, 2008.

[9] A. Mauro, "Satellite cell of skeletal muscle fibers," The Journal of Biophysical and Biochemical Cytology, vol. 9, no. 2, pp. 493-495, 1961.

[10] S. B. Chargé and M. A. Rudnicki, "Cellular and molecular regulation of muscle regeneration," Physiological Reviews, vol. 84, no. 1, pp. 209-238, 2004.

[11] A. Scaramozza, V. Marchese, V. Papa et al., "Skeletal muscle satellite cells in amyotrophic lateral sclerosis," Ultrastructural Pathology, vol. 38, no. 5, pp. 295-302, 2014.

[12] P.-F. Pradat, A. Barani, J. Wanschitz et al., "Abnormalities of satellite cells function in amyotrophic lateral sclerosis," Amyotrophic Lateral Sclerosis, vol. 12, no. 4, pp. 264-271, 2011.

[13] A. Ludolph, V. Drory, O. Hardiman et al., "A revision of the El Escorial criteria-2015," Amyotrophic Lateral Sclerosis and Frontotemporal Degeneration, vol. 16, no. 5-6, pp. 291-292, 2015.

[14] P. H. Gordon, R. G. Miller, and D. H. Moore, "ALSFRS-R," Amyotrophic Lateral Sclerosis and other Motor Neuron Disorders, no. 5, supplement 1, pp. 90-93, 2004.

[15] B. Guerra, M. C. Gómez-Cabrera, J. G. Ponce-González et al., "Repeated muscle biopsies through a single skin incision do not elicit muscle signaling, but IL-6 mRNA and STAT3 phosphorylation increase in injured muscle," Journal of Applied Physiology, vol. 110, no. 6, pp. 1708-1715, 2011.

[16] C. Suetta, U. Frandsen, L. Jensen et al., "Aging affects the transcriptional regulation of human skeletal muscle disuse atrophy," PLoS ONE, vol. 7, no. 12, Article ID e51238, 2012.

[17] J. Vandesompele, K. De Preter, F. Pattyn et al., "Accurate normalization of real-time quantitative RT-PCR data by geometric 
averaging of multiple internal control genes," Genome Biology, vol. 3, no. 7, Article ID research0034.1, 2002.

[18] J. G. Yu and L. E. Thornell, "Desmin and actin alterations in human muscles affected by delayed onset muscle soreness: a high resolution immunocytochemical study," Histochemistry and Cell Biology, vol. 118, no. 2, pp. 171-179, 2002.

[19] D. R. Marsh, J. A. Carson, L. N. Stewart, and F. W. Booth, "Activation of the skeletal $\alpha$-actin promoter during muscle regeneration," Journal of Muscle Research and Cell Motility, vol. 19, no. 8, pp. 897-907, 1998.

[20] E. W. Stilwill and V. Sahgal, "Histochemical and morphologic changes in skeletal muscle following cervical cord injury: a study of upper and lower motor neuron lesions," Archives of Physical Medicine and Rehabilitation, vol. 58, no. 5, pp. 201-206, 1977.

[21] Y. Iwasaki, H. Sugimoto, K. Ikeda, K. Takamiya, T. Shiojima, and M. Kinoshita, "Muscle morphometry in amyotrophic lateral sclerosis," The International Journal of Neuroscience, vol. 58, no. 3-4, pp. 165-170, 1991.

[22] M. M. Q. Froes, F. Kristmundsdottir, M. Mahon, and W. J. K. Cumming, "Muscle morphometry in motor neuron disease," Neuropathology and Applied Neurobiology, vol. 13, no. 6, pp. 405-419, 1987.

[23] N. R. Cashman, J. Covault, R. L. Wollman, and J. R. Sanes, "Neural cell adhesion molecule in normal, denervated, and myopathic human muscle," Annals of Neurology, vol. 21, no. 5, pp. 481-489, 1987.

[24] U. Carraro, S. Boncompagni, V. Gobbo et al., "Persistent muscle fiber regeneration in long term denervation. Past, present, future," European Journal of Translational Myology, vol. 25, no. 2, pp. 77-92, 2015.

[25] K. Doppler, M. Mittelbronn, and A. Bornemann, "Myogenesis in human denervated muscle biopsies," Muscle \& Nerve, vol. 37, no. 1, pp. 79-83, 2008.

[26] C. Suetta, U. Frandsen, A. L. Mackey et al., "Ageing is associated with diminished muscle re-growth and myogenic precursor cell expansion early after immobility-induced atrophy in human skeletal muscle," The Journal of Physiology, vol. 591, no. 15, pp. 3789-3804, 2013.

[27] S. Ishimoto, I. Goto, M. Ohta, and Y. Kuroiwa, "A quantitative study of the muscle satellite cells in various neuromuscular disorders," Journal of the Neurological Sciences, vol. 62, no. 1-3, pp. 303-314, 1983.

[28] R. Manzano, J. M. Toivonen, A. C. Calvo et al., "Altered in vitro proliferation of mouse SOD1-G93A skeletal muscle satellite cells," Neurodegenerative Diseases, vol. 11, no. 3, pp. 153-164, 2013.

[29] R. Eftimie, H. R. Brenner, and A. Buonanno, "Myogenin and MyoD join a family of skeletal muscle genes regulated by electrical activity," Proceedings of the National Academy of Sciences of the United States of America, vol. 88, no. 4, pp. 1349-1353, 1991.

[30] S. K. Panguluri, S. Bhatnagar, A. Kumar et al., "Genomic profiling of messenger RNAs and MicroRNAs reveals potential mechanisms of TWEAK-induced skeletal muscle wasting in mice," PLoS ONE, vol. 5, no. 1, Article ID e8760, 2010.

[31] K. Goljanek-Whysall, H. Pais, T. Rathjen, D. Sweetman, T. Dalmay, and A. Münsterberg, "Regulation of multiple target genes by miR-1 and miR-206 is pivotal for $\mathrm{C} 2 \mathrm{C} 12$ myoblast differentiation," Journal of Cell Science, vol. 125, no. 15, pp. 3590$3600,2012$.

[32] D. Zhang, X. Li, C. Chen et al., "Attenuation of p38-Mediated miR-1/133 expression facilitates myoblast proliferation during the early stage of muscle regeneration," PLoS ONE, vol. 7, no. 7, Article ID e41478, 2012.

[33] G. Valdez, M. P. Heyer, G. Feng, and J. R. Sanes, "The role of muscle microRNAs in repairing the neuromuscular junction," PLoS ONE, vol. 9, no. 3, Article ID e93140, 2014.

[34] J. M. Toivonen, R. Manzano, S. Oliván et al., "MicroRNA-206: a potential circulating biomarker candidate for amyotrophic lateral sclerosis," PLoS ONE, vol. 9, no. 2, Article ID e89065, 2014.

[35] L. Elia, R. Contu, M. Quintavalle et al., "Reciprocal regulation of microRNA-1 and insulin-like growth factor-1 signal transduction cascade in cardiac and skeletal muscle in physiological and pathological conditions," Circulation, vol. 120, no. 23, pp. 2377$2385,2009$.

[36] M.-B. Huang, H. Xu, S.-J. Xie, H. Zhou, and L.-H. Qu, "Insulinlike growth factor-1 receptor is regulated by microRNA-133 during skeletal myogenesis," PLoS ONE, vol. 6, no. 12, Article ID e29173, 2011.

[37] M. A. O’Reilly, "Redox activation of p21Cip1/WAF1/Sdil: a multifunctional regulator of cell survival and death," Antioxidants \& Redox Signaling, vol. 7, no. 1-2, pp. 108-118, 2005.

[38] S. J. Lees, T. E. Childs, and F. W. Booth, "p21 Cip1 expression is increased in ambient oxygen, compared to estimated physiological (5\%) levels in rat muscle precursor cell culture," Cell Proliferation, vol. 41, no. 2, pp. 193-207, 2008.

[39] J. Sellathurai, S. Cheedipudi, J. Dhawan, H. D. Schrøder, and M. Sampaolesi, "A novel in vitro model for studying quiescence and activation of primary isolated human myoblasts," PLOS ONE, vol. 8, no. 5, Article ID e64067, 2013.

[40] J. V. Chakkalakal, J. Christensen, W. Xiang et al., "Early forming label-retaining muscle stem cells require p27kip1 for maintenance of the primitive state," Development, vol. 141, no. 8, pp. 1649-1659, 2014.

[41] M. V. Chakravarthy, T. W. Abraha, R. J. Schwartz, M. L. Fiorotto, and F. W. Booth, "Insulin-like growth factor-I extends in vitro replicative life span of skeletal muscle satellite cells by enhancing G1/S cell cycle progression via the activation of phosphatidylinositol 3'-kinase/Akt signaling pathway," The Journal of Biological Chemistry, vol. 275, no. 46, pp. 35942-35952, 2000. 


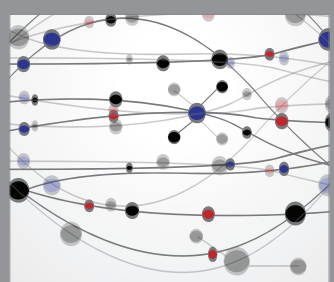

The Scientific World Journal
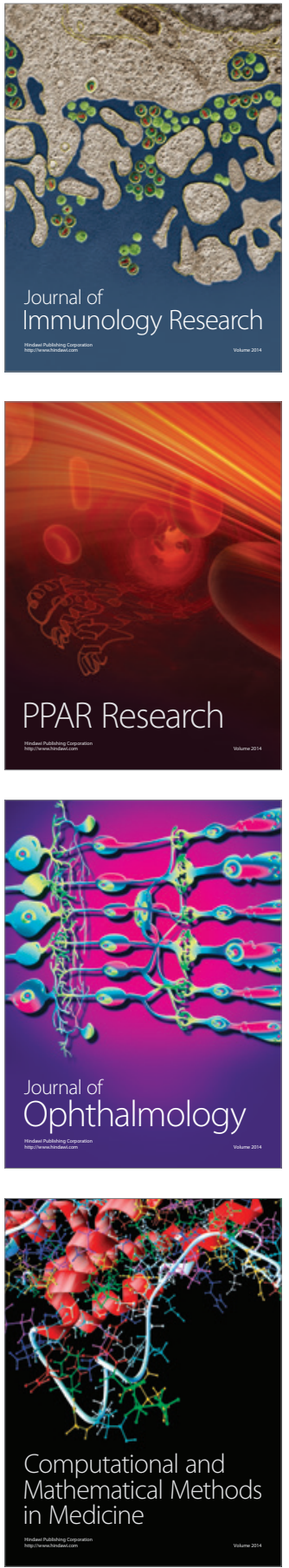

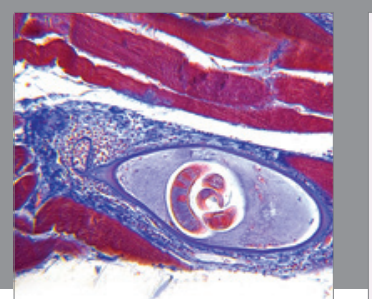

Gastroenterology Research and Practice

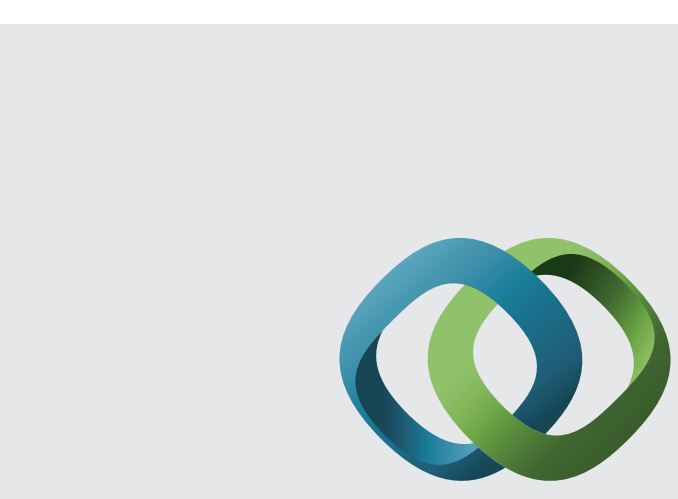

\section{Hindawi}

Submit your manuscripts at

http://www.hindawi.com
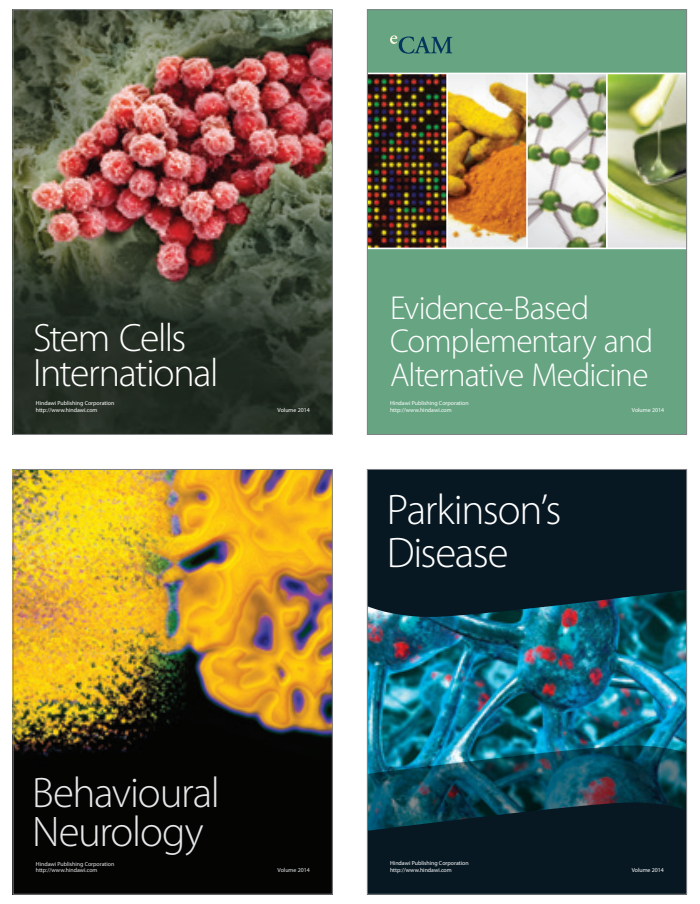
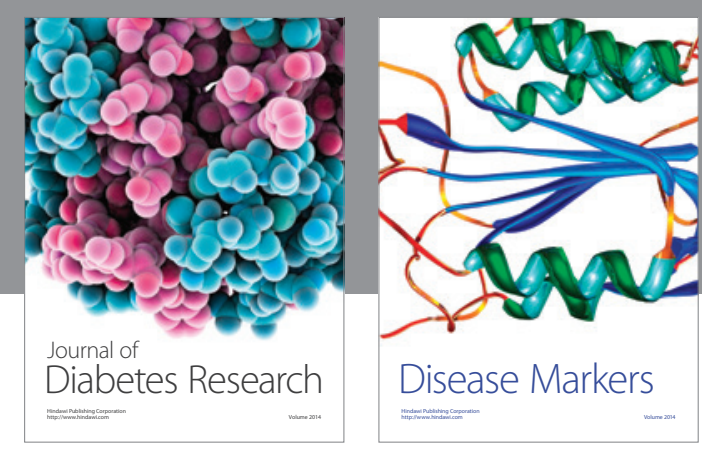

Disease Markers
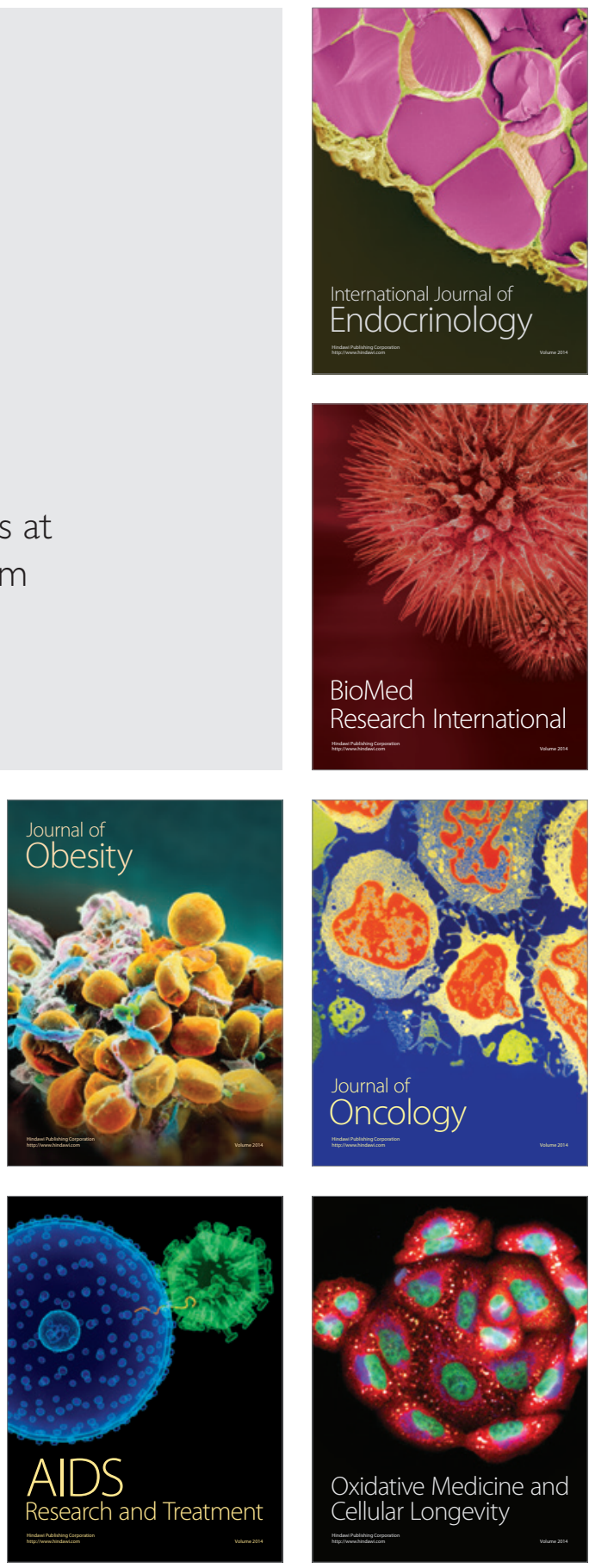